HPFRCC7: 7th workshop on High Performance Fiber Reinforced Cement Composites, 1-3, June 2015, Stuttgart, Germany.

\title{
CAST-ON SITE UHPFRC FOR IMPROVEMENT OF EXISTING STRUCTURES - ACHIEVEMENTS OVER THE LAST 10 YEARS IN PRACTICE AND RESEARCH
}

\section{Emmanuel Denarié (1), Eugen Brühwiler (1)}

(1) Division of Maintenance and Safety of Structures (MCS-IIC-ENAC), Ecole Polytechnique Fédérale de Lausanne (EPFL), GC B2-435, Station 18, CH-1015 Lausanne, Switzerland, fax. +41 2169358 85, email: emmanuel.denarie@epfl.ch.

Keywords: UHPFRC, Strain Hardening, protection, reinforcement, rheology

\begin{abstract}
The first cast-on site application of UHPFRC in Switzerland took place for the rehabilitation and widening of the bridge over river La Morge in 2004. Since then, over the last 10 years, this technology spread successfully in Switzerland for bridges and buildings under the impulse of MCS/EPFL and is now current practice. Tests performed on the bridge over La Morge in 2014 showed that chloride penetration is extremely limited as expected and that the UHPFRC behaves fully according to the expectations. This is indeed the first time that the performance of cast-on site UHPFRC without thermal treatment is validated over such a long period of time.

This paper highlights recent achievements of cast-on site applications of UHPFRC in Switzerland and abroad (Slovenia and France), with various types of UHPFRC including green mixes with limited clinker content. Associated research progresses over related fields are put into perspective with the practical applications. Results of chloride penetration over 10 years in a UHPFRC overlay are discussed in comparison with the performance of concretes used on bridge decks.
\end{abstract}

Total number of pages of the paper (this one excluded): 8 


\title{
CAST-ON SITE UHPFRC FOR IMPROVEMENT OF EXISTING STRUCTURES - ACHIEVEMENTS OVER THE LAST 10 YEARS IN PRACTICE AND RESEARCH
}

\author{
Emmanuel Denarié (1), Eugen Brühwiler (1) \\ (1) MCS, Ecole Polytechnique Fédérale de Lausanne, Switzerland
}

\begin{abstract}
The first cast-on site application of UHPFRC in Switzerland took place for the rehabilitation and widening of the bridge over river La Morge in 2004. Since then, over the last 10 years, this technology spread successfully in Switzerland for bridges and buildings under the impulse of MCS/EPFL and is now current practice. Tests performed on the bridge over La Morge in 2014 showed that chloride penetration is extremely limited as expected and that the UHPFRC behaves fully according to the expectations. This is indeed the first time that the performance of cast-on site UHPFRC without thermal treatment is validated over such a long period of time.
\end{abstract}

This paper highlights recent achievements of cast-on site applications of UHPFRC in Switzerland and abroad (Slovenia and France), with various types of UHPFRC including green mixes with limited clinker content. Associated research progresses over related fields are put into perspective with the practical applications. Results of chloride penetration over 10 years in cast on site UHPFRC are discussed in comparison with the performance of concretes used on bridge decks.

\section{INTRODUCTION}

The concept of application of Strain-Hardening Ultra-High Performance Fiber Reinforced Cement Composites (SH-UHPFRC) for the rehabilitation of structural members, proposed by Brühwiler in 1999 is schematically illustrated on Fig. 1. A dense layer of UHPFRC with 25 to $60 \mathrm{~mm}$ thickness is applied on the superstructure in zones of severe environmental and mechanical loads (exposure classes XD2, XD3) and only where the UHPFRC fits the requirements. The construction process becomes simpler, quicker, and more robust, with an optimal use of composite construction. The waterproofing capabilities of UHPFRC exempt from applying a waterproofing membrane. Thus, the asphalt pavement can be applied after only 8 days of moist curing of the SH-UHPFRC, in a wide range of climatic conditions. This constitutes a very significant time saving with respect to the drying period of up to 3 weeks necessary prior to the application of a waterproofing membrane for a usual mortar or concrete and to their limited durability.

The thickness of the asphalt layer can also be limited to the absolute minimum required for the traffic loads. It is not needed to increase it to apply weight on the waterproofing membrane to prevent the formation of air pockets. 
Cast-on site applications require Strain Hardening UHPFRC able to withstand the development of eigenstresses due to restrained shrinkage, without cracking. Their rheology can be adjusted from self-compacting to thixotropic for application on inclined substrates. Their tensile response must be validated on specimens representative of the application (fiber orientation and rheology).

When it is required, the combination of the protective properties and deformation capability of UHPFRC with the mechanical performance of reinforcement bars (normal or high grade) provides a simple and efficient way of increasing the stiffness and load-carrying capacity with compact cross sections of 40 to $70 \mathrm{~mm}$ thickness. Reinforcement bars also help mitigate the variability of the tensile response of UHPFRC over large surfaces.

These concepts have been validated by means of extensive research aimed at characterizing UHPFRC materials and the structural behavior of composite UHPFRC-RC structural members, as well as numerous successful applications in Switzerland and abroad, since 2004 [1-6]. They are very well suited for bridges and reinforcement of slabs in buildings and can also be implemented for galleries, tunnels, retaining walls or maritime structures.

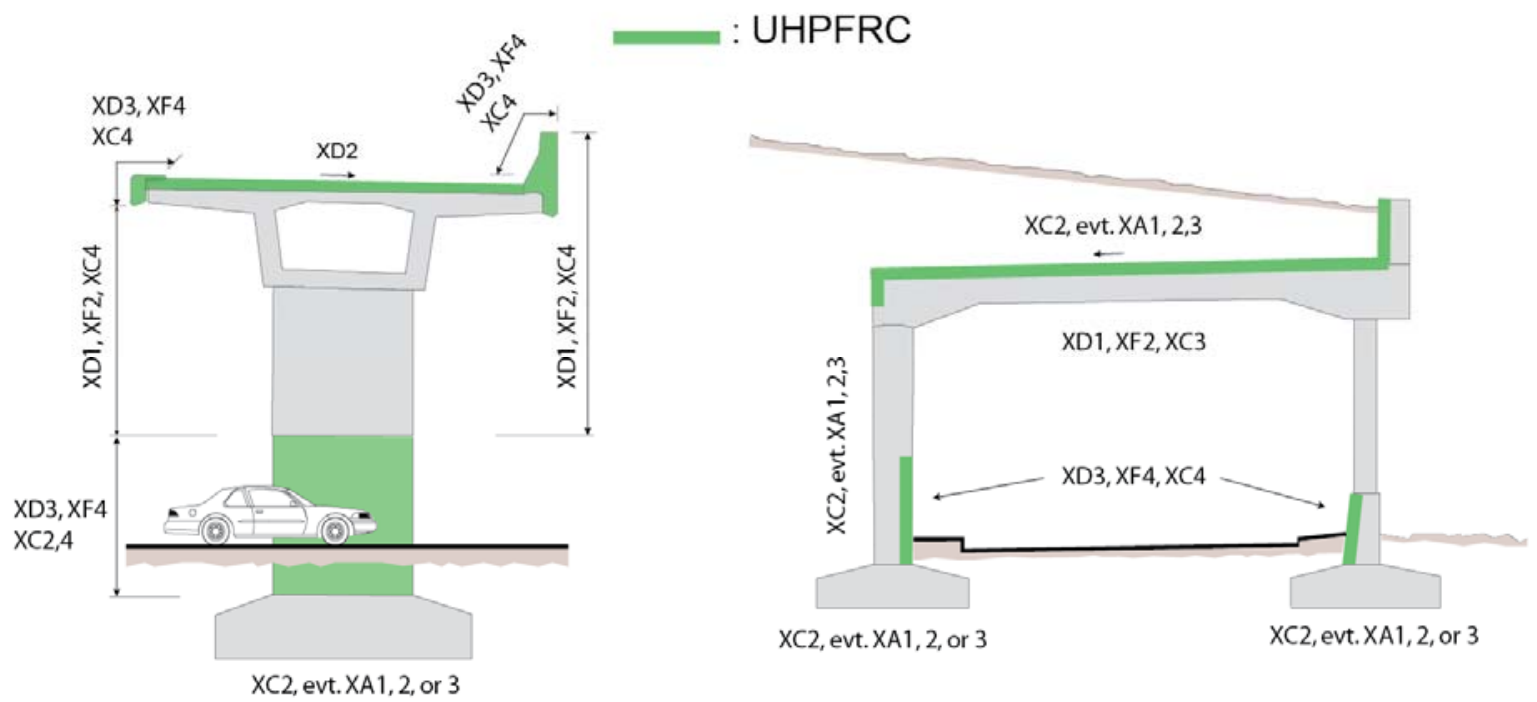

Figure 1: concepts of application of the local "hardening" of structures with UHPFRC.

This paper highlights recent achievements of cast-on site applications of UHPFRC in Switzerland and abroad (Slovenia and France), with various types of UHPFRC including green mixes with limited clinker content. Associated research progresses over related fields are put into perspective with the practical applications.

Results of chloride penetration over 10 years in cast on site UHPFRC are discussed in comparison with the performance of concretes used on bridge decks. 


\section{CAST-ON SITE UHPFRC}

\subsection{Optimization of rheology and characterization}

Workability is the first and most critical issue to face when developing/applying UHPFRC, especially in the case of cast in place mixes which require tensile strain hardening (thus a high fiber dosage) and a thixotropic behavior at fresh state. Moreover, the development of UHPFRC mixes with local components is often a challenge due to cement-superplasticizer compatibility issues. The workability barrier encountered when using pure local cements is illustrated on Figure 2 from a case study of development of UHPFRC with Slovenian products [5]. The mini slump cone test is applied to two UHPC matrix mixes. One with pure CEM I 52.5 from Salonit (Slovenia) and the other with $50 \%$ mass of the same cement and 50 $\%$ of Durcal 15 (OMYA) limestone filler. Both mixes have similar superplasticizer dosages $(2.5 \%$ total mass Cement + Filler $)$ and very close silica fume dosages $\left(200\right.$ or $\left.210 \mathrm{~kg} / \mathrm{m}^{3}\right)$. The results are shown in Table 1.

In case a, it is impossible to achieve sufficient workability when fibers are added. In case b, excellent workability is obtained, comparable to reference UHPFRC mixes developed in France and Switzerland for a former project [6]. This matrix is perfectly adapted for addition of fibers at high dosages (from 3 to $9 \%$ vol.) to achieve robust tensile strain hardening properties.

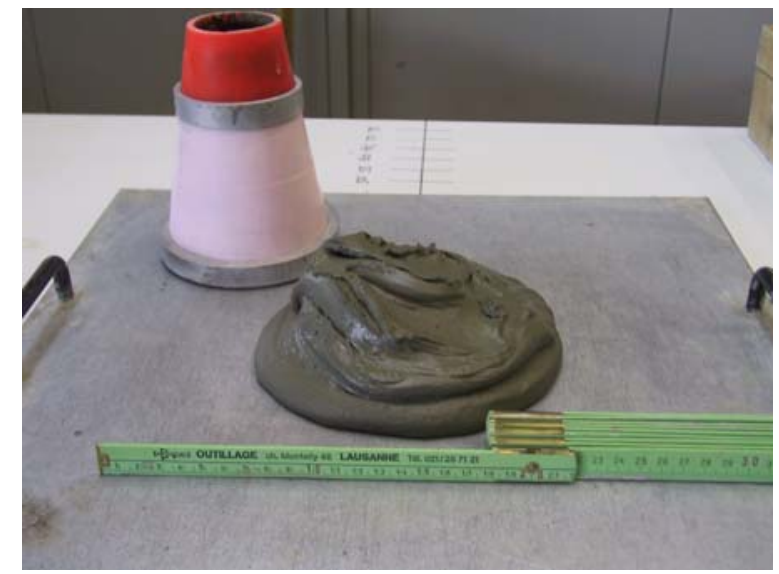

a)

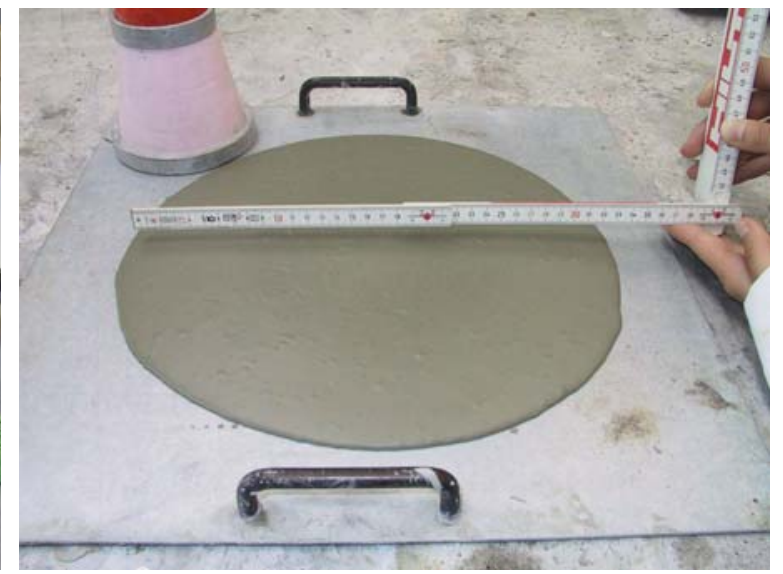

b)

Figure 2: Mini-slump test results, UHPC mixes without a), or with b) blending with limestone filler.

Following this concept, the effective water/cement ratio of the mix is significantly increased and the degree of hydration at the same age too, without affecting the UHPFRC performance (mechanical and protective) as shown in [6]. The limestone filler just replaces unhydrated cement, with a dramatic improvement of workability, thus allowing the realization of UHPFRC well suited for cast in-situ applications of rehabilitation, with virtually any locally available cement and superplasticizer. This concept also significantly reduces the monetary cost and environmental impact of UHPFRC, by decreasing to a large extend their clinker content, $[7,8]$. 
Table 1: Mini cone workability test results, influence of cement replacement by limestone filler.

\begin{tabular}{ccccccccc}
\hline Case & $\begin{array}{l}\text { Cement } \\
{\left[\mathrm{kg} / \mathrm{m}^{3}\right]}\end{array}$ & $\begin{array}{l}\text { Limestone } \\
\text { Filler } \\
{\left[\mathrm{kg} / \mathrm{m}^{3}\right]}\end{array}$ & $\begin{array}{l}\text { Silica } \\
\text { fume } \\
{\left[\mathrm{kg} / \mathrm{m}^{3}\right]}\end{array}$ & $\begin{array}{l}\mathrm{SF} / \mathrm{SF}) \\
{[---]}\end{array}$ & $\begin{array}{l}\mathrm{t}_{250} \\
{[\mathrm{~s}]}\end{array}$ & $\begin{array}{l}\mathrm{D}_{1,2} \\
{[\mathrm{~mm}]}\end{array}$ & $\begin{array}{l}\text { Daverage } \\
{[\mathrm{mm}]}\end{array}$ & $\begin{array}{l}\text { Slump } \\
{[\mathrm{mm}]}\end{array}$ \\
\hline $\mathrm{a}$ & 1614 & 0 & 210 & 0.13 & $\infty$ & $170 / 170$ & 170 & 90 \\
\hline $\mathrm{b}$ & 770 & 770 & 200 & 0.26 & 9,3 & $390 / 410$ & 400 & n.a. \\
\hline
\end{tabular}

NB: Mini-slump $(\varnothing=48 / 105 \mathrm{~mm}, \mathrm{~h}=150 \mathrm{~mm})$ : determination of $(1) \mathrm{t}_{250}=$ time to flow at $250 \mathrm{~mm}$ diameter, (2) $\mathrm{D}_{1,2}=$ diameters when flow is stopped, in two perpendiculars directions, (3) If applicable, $s=$ slump with respect to top of mini-cone.

The range of workability of the UHPFRC mixes developed at MCS and applied for cast on site applications varies from self-compacting (slump flow class SF2 - 700 to $800 \mathrm{~mm}$ spread after EN 206-9) to thixotropic with a residual slump of 200 to $250 \mathrm{~mm}$ (apparent yield stress after Herschel-Buckley of 600 to $800 \mathrm{~Pa}$, following the calibrations given in [9]) for casting on substrates with 5 to $12 \%$ slopes.

\subsection{Examples of application}

The first application of UHPFRC on a bridge, following the concepts developed at MCS, took place in 2004, on the bridge over river La Morge (10 m span, 2 lanes) in Wallis, Switzerland. At that time $6 \mathrm{~m}^{3}$ UHPFRC were cast to widen the bridge, rehabilitate the curbs and protect the deck [6], Figure 3a).

Since 2004 over 35 successful applications on bridges, building slabs, and maritime structures have taken place in Switzerland and abroad (Slovenia - 2009 and France - 2013).

This technology was raised to a fully industrialized level (by using a machine for casting on the deck surface) for the reinforcement of the Chillon viaducts (Swiss Highways, $2.1 \mathrm{~km}$ long), with a total of $2400 \mathrm{~m}^{3}$ UHPFRC to be laid between 2014 and 2015 in the very limited time span of a few months each summer, Figure $3 b$ ).

The $65 \mathrm{~m}$ long Log Čezsoški bridge over the Soča river (northwest of Slovenia) was rehabilitated in 2009, [7], with thixotropic green UHPFRC developed from Slovenian components, according to the concepts described in [5]. It has only one lane with $5 \%$ longitudinal slope and a frequent traffic as it is the only link between the two sides of the river within $15 \mathrm{~km}$. The cross section of the bridge, with the concept of rehabilitation is shown on Figure 4a). A continuous UHPFRC overlay is applied to protect the full upper face of the bridge deck, footpath and external faces of the curbs. The selected concept with no dry joints along the full cross section guarantees a continuous protection. The application was successful and fast (1 month instead of 3 month with traditional techniques). A survey of the bridge condition was realized in 2011 after 2 years exposure and the onsite determined protective properties (air permeability and capillary absorption) were excellent, according to the expectations [10], Figure 4b). 


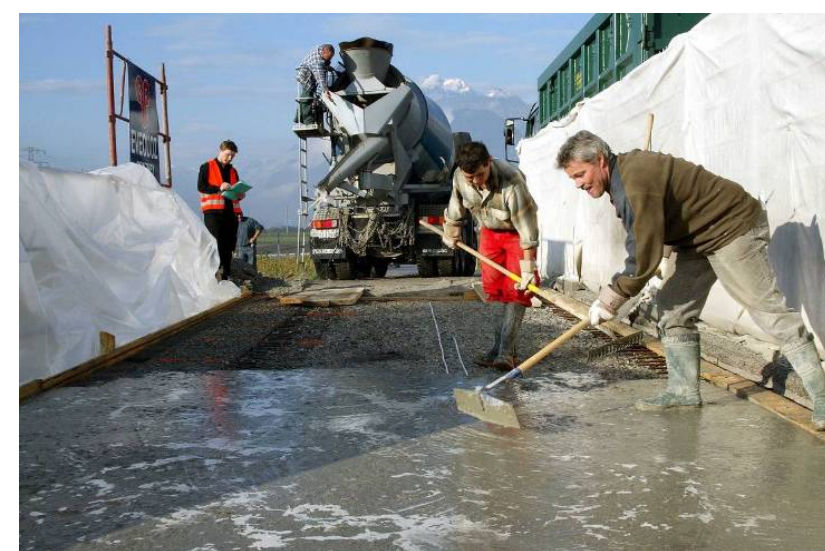

a)

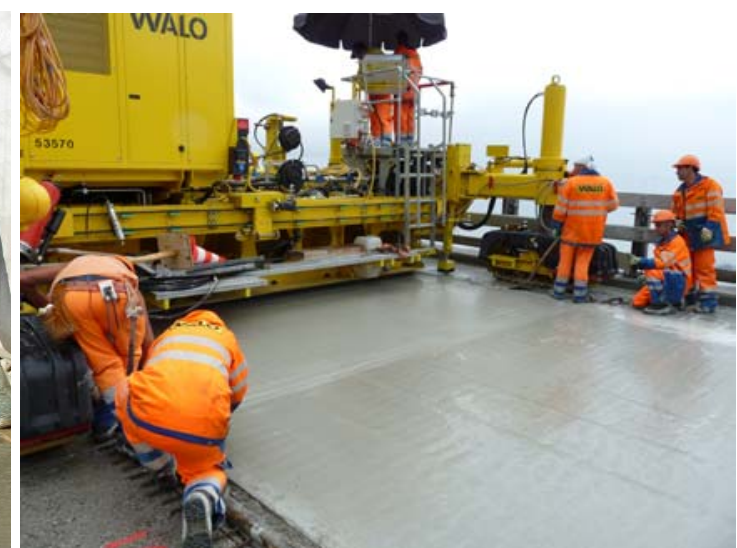

b)

Figure 3: Application of UHPFRC. a) Bridge over river la Morge, Switzerland $6 \mathrm{~m}^{3}, 2004$, photo Alain Herzog, b) Chillon Viaduct, Switzerland- 2 x $1200 \mathrm{~m}^{3}-2014 / 2015$.

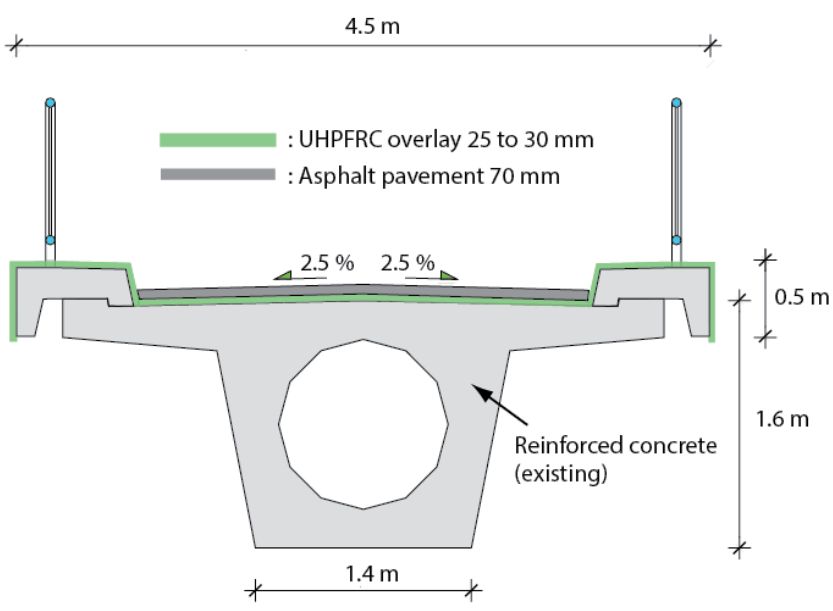

a)

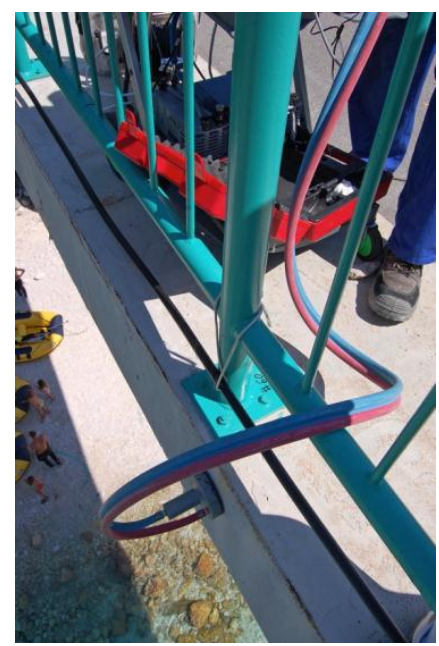

b)

Figure 4: Application of UHPFRC. Log Čezsoški bridge - Soča river - Slovenia - July 2009 , a) cross section of the bridge with concept of rehabilitation, b) air permeability tests after 2 years on lateral sides of curbs.

The concept of application of cast in place UHPFRC for the reinforcement of structures was extended to maritime signalization structures in 2013, [11]. An existing turret (5 m high) with residual swelling reactions (AAR), off the south Brittany coast nearby Lorient (France), was reinforced with a $60 \mathrm{~mm}$ UHPFRC layer. The UHPFRC was cast in place (using a helicopter to transport the fresh UHPFRC) in a formwork around the existing masonry structure, Figure 5a) and b). The UHPFRC mix was specifically tailored for this application with a tensile strain hardening response, limited shrinkage, and an optimized rheology (selfleveling) for a fast filling of the formwork to minimize the use of helicopter time. The casting of the UHPFRC on the Turret by helicopter was fast ( 2 hours for $4.2 \mathrm{~m}^{3}$ UHPFRC) and efficient. This successful application opens the way to the cast in place reinforcement of heritage lighthouses at sea, in most difficult conditions of access. 


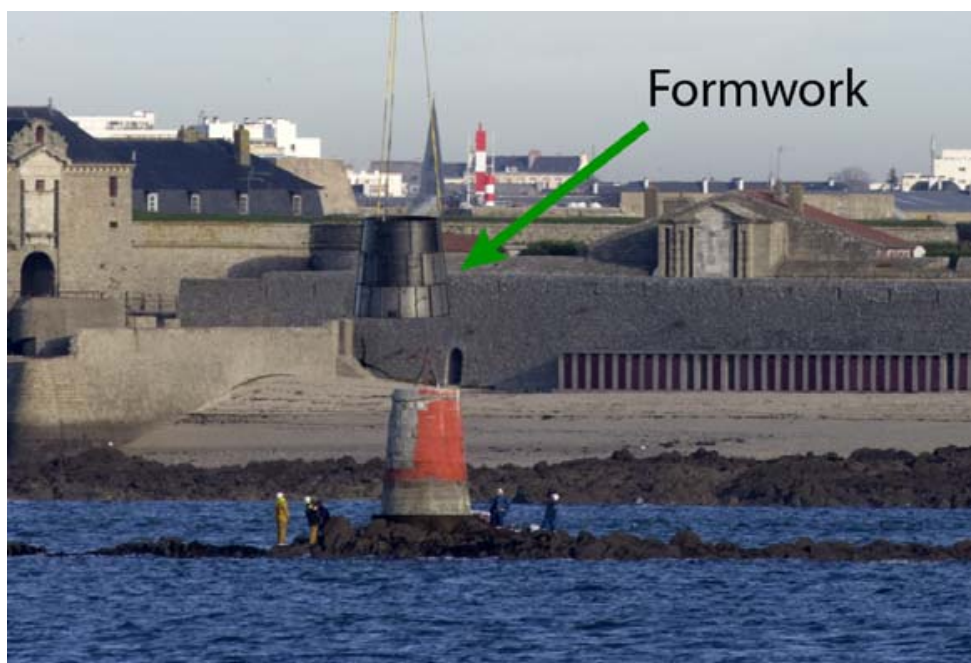

a)

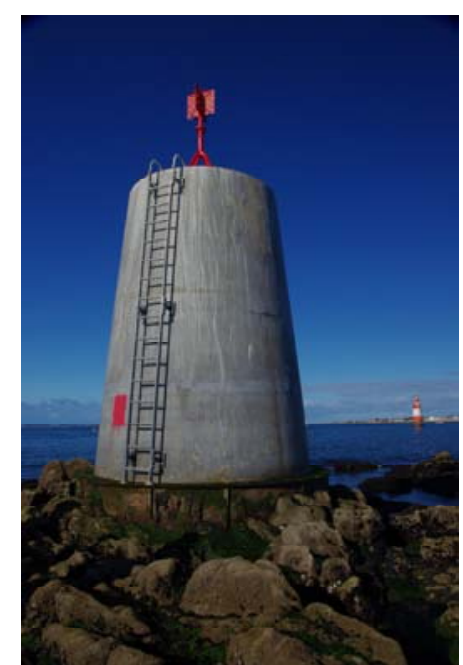

b)

Figure 5: Application of UHPFRC, Cabon turret, Brittany, France, $4.2 \mathrm{~m}^{3}$ UHPFRC applied by helicopter, 2013, a) installation of the formwork, b) finished UHPFRC surface.

\section{LONG TERM FEEDBACK OF PROTECTIVE PROPERTIES}

The protective properties of the UHPFRC applied in 2004 on the bridge over La Morge were assessed in 2014, after 10 years of severe exposure to deicing salts. Cores were taken in the curbs and deck to determine the capillary absorption coefficients and chloride profiles. As a comparison, cores were also taken in a standard repair mortar applied in 2007 on the upstream curb to fill coring holes in UHPFRC. The sorptivity of the UHPFRC (determined after EN 1925) varied between $111 \mathrm{~g} / \mathrm{m}^{2} \cdot \mathrm{h}^{0.5}$ (cast-in place overlay over upstream curb), 78 $\mathrm{g} / \mathrm{m}^{2} \cdot \mathrm{h}^{0.5}$ (prefabricated downstream curb), and $64 \mathrm{~g} / \mathrm{m}^{2} \cdot \mathrm{h}^{0.5}$ (cast-in place overlay over bridge deck). These values correspond to the ones determined in the laboratory during the optimization of the mixes before the site. For comparison, a concrete suitable to build bridge curbs (exposure classes XD3, XF4 after EN 206-1) has a sorptivity around $300 \mathrm{~g} / \mathrm{m}^{2} . \mathrm{h}^{0.5}$ when it is properly placed and cured.

The chloride profiles were determined by chemical extraction after SN EN 14629:2007 for 2 cores on each part of the structure. Figure 6a) represents the profiles in the UHPFRC samples after 10 years of exposure and the predictions of models based on Fick's law with constant diffusivity for two limit cases (lower and upper bound). Figure 6b) represents the chloride profiles in the repair mortar after 7 years exposure on the upstream curb with the predictions of a model also based on Fick's law with constant diffusivity. The initial chloride content of all the materials has been determined on the basis of their composition and taken into account in the modelling. For UHPFRC it is estimated to be around $0.5 \mathrm{~kg} / \mathrm{m}^{3}$. For the repair mortar it is unknown. The obtained diffusivities are summarized in Table 2 .

As expected, the chloride penetration in the UHPFRC is remarquably low after 10 years and the penetration in the repair mortar is already significant after 7 years. For comparison, the chloride diffusivity determined on the UHPFRC samples for the Sakata - Mirai footbridge in Japan (Heat-Treated - prefabricated UHPFRC) was in a similar range with a diffusivity of 
$4.710^{-16} \mathrm{~m}^{2} / \mathrm{s}$ for samples after 5 years exposure in the open box shaped girder of the bridge and $6.10^{-15} \mathrm{~m}^{2} / \mathrm{s}$ for samples tested in the laboratory for 2.5 years in ponding conditions [12].

The higher values on the first point of the upstream curb of the bridge over la Morge are likely to be due to a local microcrack and are not confirmed by the values on the second point, much lower.

Table 2: parameters of the chloride diffusion models

\begin{tabular}{lcccc}
\hline Material & Unit & $\begin{array}{c}\text { UHPFRC } \\
\text { Model 1 }\end{array}$ & $\begin{array}{c}\text { UHPFRC } \\
\text { Model 2 }\end{array}$ & $\begin{array}{c}\text { Repair mortar } \\
\text { Model 3 }\end{array}$ \\
\hline Diffusivity & {$\left[\mathrm{m}^{2} / \mathrm{s}\right]$} & $4.7 \times 10^{-16}$ & $4 \times 10^{-15}$ & $1 \times 10^{-13}$ \\
\hline
\end{tabular}

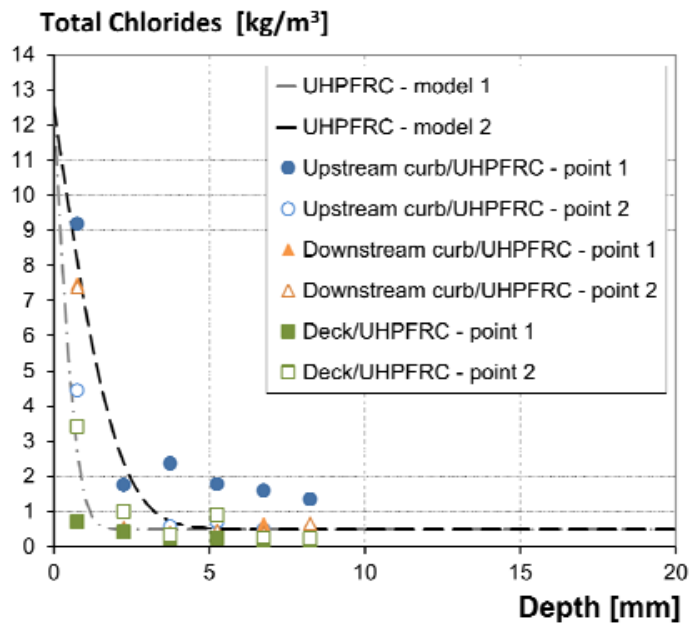

a)

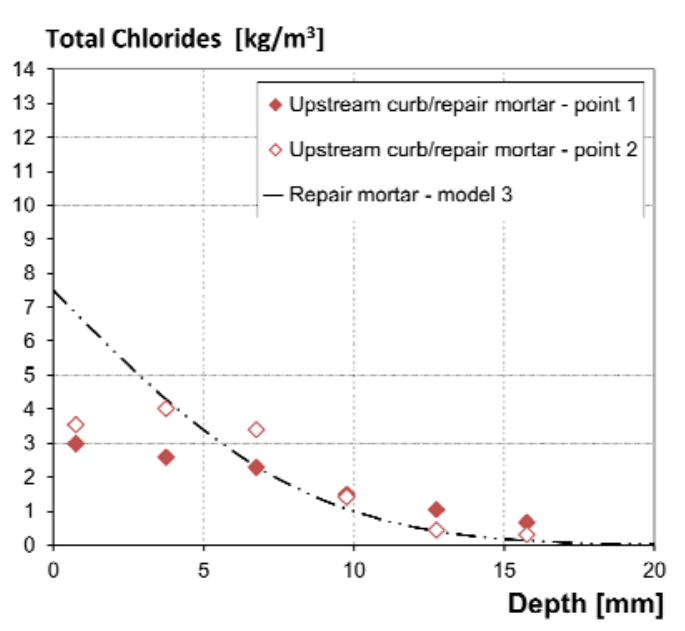

b)

Figure 6: Chloride profiles after 10 years of exposure, bridge over river la Morge, a) UHPFRC, b) repair mortar applied in coring holes after 3 years exposure (age: 7 years), UHPFRC layer of 25 to $35 \mathrm{~mm}$ thickness over existing concrete.

\section{CONCLUSIONS}

- The concept of application of strain hardening UHPFRC for the improvement of existing structures has been applied successfully on numerous structures in Switzerland and abroad since 2004 .

- Combination of UHPFRC with rebars offers an efficient way to produce highly durable R-UHPFRC tensile membranes to reinforce existing structures.

- This efficient technology has been developed over the years to be usable in the most challenging conditions and most recently with industrial quantities cast per day (up to $80 \mathrm{~m}^{3}$ ), over several months to reinforce a $2.1 \mathrm{~km}$ long highway viaduct in Switzerland. 
- The continuous incentive of practical applications triggered associated R\&D activities and helped keep a clear vision of the relevant topics to be investigated and testing methodologies to be used.

- The excellent protective properties of cast-in place UHPFRC have been demonstrated over 10 years of field exposure, and the chloride diffusivities are similar to those determined for other applications on heat-treated prefabricated UHPFRC.

\section{ACKNOWLEDGEMENTS}

This paper summarizes research activities of MCS on UHPFRC at EPFL, and it is referred mostly to own articles. References to contributions by other research groups and researchers can be found in the listed papers.

\section{REFERENCES}

[1] Brühwiler E., Denarié E., 'Rehabilitation and strengthening of concrete structures with Ultra High Performance Fiber Reinforced Concretes', Structural Engineering International, IABSE, (04/2013).

[2] Denarié E., Brühwiler E., 'Strain Hardening Ultra-high Performance Fibre Reinforced Concrete: Deformability versus Strength Optimization', International Journal for Restauration of Buildings and Monuments, Aedificatio, Vol. 17, n ${ }^{\circ}$ 6, (2011) 397-410.

[3] Denarié E., Brühwiler E., 'Structural rehabilitations with Ultra High Performance Fibre Reinforced Concretes', International Journal for Restauration of Buildings and Monuments, Aedificatio, Vol. 12, No. 5 and 6, (2006) 453-465.

[4] Denarié E., Šajna A., , 'Composite UHPFRC-concrete construction - harden structures to last', CCC-2009: The 5th Central European Congress on Concrete Engineering, September 24-25, 2009, Baden, Austria, Edited by Austrian Society for Concrete and Construction Technology, (2009) 80-83.

[5] Denarié E. 'Recommendations for the tailoring of UHPFRC recipes for rehabilitation'. Deliverable ARCHES D06, http://arches.fehrl.org. (2009).

[6] Denarié E.,'Full scale application of UHPFRC for the rehabilitation of bridges - from the lab to the field', deliverable SAMARIS D22 http://samaris.zag.si/ (2006).

[7] Denarié E.; Habert G.; Šajna A.: "Recommendations for the use of UHPFRC in composite structural members - rehabilitation Log Čezsoški bridge". Deliverable ARCHES D14, http://arches.fehrl.org, (2009).

[8] Habert, G., Denarié, E., Šajna, A., Rossi, P., 'Lowering the global warming impact of bridge rehabilitations by using Ultra High Performance Fibre Reinforced Concretes', Cement and Concrete Composites, 38, (2013) 1-11.

[9] Ferraris C., de Larrard F., 'Testing and Modelling of Fresh Concrete Rheology', NIST, Report NISTIR 6094, USA (1998).

[10] Šajna A, Denarié E, Bras V., 'Assessment of a UHPFRC bridge rehabilitation in Slovenia, two years after application', 3rd International Symposium on Ultra-High Performance Concrete HiPerMat, Kassel, Germany, (2012) 937-944.

[11]Denarié E., Jacomo D., Fady N., Corvez D., 'Rejuvenation of maritime signalization structures with UHPFRC', in Proceedings UHPFRC 2013, $2^{\text {nd }}$ International Symposium on Ultra-High Performance Fibre-Reinforced Concrete (UHPFRC), Marseille, AFGC, (2013) 157-166.

[12] Tanaka Y., Musha H., Tanaka S., Ishida M., 'Durability performance of UFC Sakata-Mirai footbridge under sea environment', Proceedings Framcos 7, B. H. Oh, et al. (eds) (2010) 16481654. 